\title{
PENGARUH KOMPENSASI PERUSAHAAN TERHADAP KINERJA KARYAWAN PT.BARUNA MITRA SEGARA LINES PANJANG DI BANDAR LAMPUNG
}

\author{
${ }^{1}$ Radite Husin, ${ }^{2}$ Triono Ade Hirmawan \\ Raditee Husin $^{(1)^{*}}$, Triono Ade Hirmawan ${ }^{(2)}$ \\ Fakultas Ekonomi Universitas Sang Bumi Ruwa Jurai \\ *email:raditeehusin@gmail.com
}

\begin{abstract}
Abstrak. Penelitian ini bertujuan untuk mengetahui pengaruh kompensasi yang diberikan perusahaan terhadap kinerja karyawan di PT. Baruna Mitra Segara Lines Panjang di Bandar Lampung. Metode yang digunakan dalam penelitian ini menggunakan kuantitatif deskriptif. Berdasarkan hasil penelitian kompensasi perusahaan berpengaruh positif dan signifikan terhadap kinerja karyawan PT. Baruna Mitra Segara Lines Panjang di Bandar Lampung yang dilihat dari nilai thitung sebesar 7.696 sedangkan tabel sebesar 1.671, jadi thitung 7.696 lebih besar $t_{\text {tabel }}$ 1.671, serta nilai signifikasi (sig t) sebesar 0.000 kurang dari 0.05. Selain itu dilihat dari analisis diperoleh nilai atas Koefesien Determinasi ( $R$ Square) sebesar 0.505, sehingga kompensasi perusahaan memiliki pengaruh sebesar 50.5\% terhadap kinerja karyawan PT. Baruna Mitra Segara Lines Panjang di Bandar Lampung.
\end{abstract}

Kata Kunci: Kompensasi, Kinerja, Karyawan.

Abstract : Abstract. This study aims to determine the effect of compensation provided by the company on the performance of employees at PT. Baruna Mitra Segara Long Lines in Bandar Lampung. The method used in this research is descriptive quantitative. Based on the results of the research, the company's compensation has a positive and significant effect on the performance of the employees of PT. Baruna Mitra Segara Lines Panjang in Bandar Lampung as seen from the tcount value of 7,696 while the ttable of 1,671, so tcount of 7,696 is greater than table of 1,671, and the significance value (sig t) of 0.000 is less than 0.05. In addition, seen from the analysis obtained by the value of the Coefficient of Determination ( $R$ Square) of 0.505, so that the company's compensation has an influence of $50.5 \%$ on the performance of employees of PT. Baruna Mitra Segara Long Lines in Bandar Lampung.

Keyword: Compensations, Performance, Employees.

\section{PENDAHULUAN}

Persaingan yang semakin ketat dan kompetitif menyebabkan perusahaan dituntut untuk mampu meningkatkan daya saing dalam rangka menjaga kelangsungan hidup perusahaan. Hampir di semua perusahaan mempunyai tujuan yaitu 
memaksimalkan keuntungan dan nilai bagi perusahaan, dan juga untuk meningkatkan kesejahteraan pemilik dan karyawan.

Karyawan merupakan unsur terpenting dalam menentukan maju mundurnya suatu perusahaan. Untuk mencapai tujuan perusahaan diperlukan karyawan yang sesuai dengan persyaratan dalam perusahaan dan juga harus mampu menajalankan tugas-tugas yang telah ditentukan oleh perusahaan. Karyawan dapat bekerja dengan baik bila memilik kinerja yang tinggi sehingga dapat menghasilkan kerja yang baik. Menurut Keith Davis dalam Mangkunegara (2015:13), ada dua faktor utama yang mempengaruhi kinerja yakni kemampuan (ability) dan motivasi (motivation) individu tersebut.

Kemampuan karyawan tercermin dari kinerja, kinerja yang baik adalah kinerja yang optimal. Kinerja karyawan tersebut merupakan salah satu modal bagi perusahaan untuk mencapai tujuannya sehingga kinerja karyawan adalah hal yang patut diperhatikan oleh pemimpin perusahaan. Kinerja pada umumnya diartikan sebagai kesuksesan seseorang dalam melaksanakan suatu pekerjaan. Kinerja karyawan merupakan hasil kerja yang dicapai seseorang dalam melaksanakan tugas-tugas yang dibebankan kepadanya untuk mencapai target kerja.

Prawirosentono (2017:2), mengatakan bahwa kinerja adalah hasil kerja yang dapat dicapai oleh pegawai atau sekelompok pegawai dalam suatu organisasi, sesuai dengan wewenang dan tanggung jawab masing-masing, dalam upaya mencapai tujuan organisasi bersangkutan secara legal, tidak melanggar hukum dan sesuai dengan moral dan etika.

Penilaian kinerja merupakan upaya membandingkan prestasi aktual karyawan dan prestasi kerja yang diharapkan darinya. Jika kinerja tidak sesuai dengan standar, maka untuk menyusun rencana peningkatan kinerja dalam penilaian kinerja karyawan tidak hanya menilai secara fisik, tetapi pelaksanaan pekerjaan secara keseluruhan menyangkut berbagai bidang seperti kemampuan kerja, kerajinan, disiplin, hubungan kerja, atau hal-hal khusus sesuai dengan bidang dan tingkatan pekerjaan (Dessler dalam Lucky, 2018:174).

Menurut Murphy dan Cleveland (2018:113), mengatakan bahwa kinerja adalah kualitas perilaku yang berorientasi pada tugas atau pekerjaan. Menurut Dharma (2015:112), mengatakan bahwa kinerja adalah manifestasi dari hubungan kerakyatan antara masyarakat dengan 
pemerintah, sedangkan menurut Widodo kompeten dibidangnya tentu akan (2015:78) mengatakan bahwa kinerja mendapatkan kompensasi yang sebanding adalah melakukan suatu kegiatan dan dengan kinerja karyawan tersebut. menyempurnakannya sesuai dengan Suparyadi (2015:271) menyatakan bahwa tanggung jawabnya dengan hasil seperti kompensasi merupakan keseluruhan yang diharapkan. Sedangkan Timpe imbalan yang diterima oleh karyawan (2018:9), kinerja adalah prestasi kerja, yang ditentukan oleh faktor lingkungan dan perilaku manajemen. Hasil penelitian Timpe menunjukkan bahwa lingkungan kerja yang menyenangkan begitu penting untuk mendorong tingkat kinerja pegawai yang paling efektif dan produktif dalam interaksi sosial organisasi akan senantiasa terjadi adanya harapan bawahan terhadap atasan dan sebaliknya.

Jadi, karyawan yang produktif adalah orang yang dapat memberi sumbangan yang nyata, imaginatif dan inovatif dalam mendekati persoalan hidupnya serta mempunyai kepandaian (kreatif) dalam mencapai tujuan hidupnya, bertanggung jawab dan responsif dalam hubungannya dengan orang lain (kepemimpinan). karyawan seperti ini merupakan aset organisasi yang selalu berusaha meningkatkan diri dalam organisasinya dan akan menunjang pencapaian produktivitas organisasi.

Manajemen kompensasi didalam suatu organisasi perusahaan sangat penting. Karyawan yang memiliki kemampuan yang sebagai penghargaan atas kontribusi yang diberikan kepada organisasi, baik yang bersifat finansial maupun nonfinansial. Hasibuan (2017:118) menyatakan bahwa kompensasi adalah semua pendapatan yang berbentuk uang, barang langsung atau tidak langsung yang diterima karyawan sebagai imbalan jasa yang diberikan kepada perusahaan.

Hasibuan (2017:122), menjelaskan bahwa terdapat beberapa asas kompensasi yaitu asas adil dan asas layak serta mempertahankan undang-undang perburuhan yang berlaku. Asas adil dimaksudkan dalam besarnya kompensasi yang sesuai dengan prestasi kerja, jenis pekerjaan, tanggung jawab dan jabatan. Sedangkan Asas layak yaitu kompensasi yang disesuaikan dengan kelayakannya.

Menurut Rivai dan Ella (2017:358) kompensasi terbagi menjadi dua yaitu sebagai berikut:

1. Kompensasi Finansial, Kompensasi finansial terdiri atas dua yaitu kompensasi langsung dan kompensasi tidak langsung (tunjangan). 
Kompensasi finansial langsung. Terdiri atas pembayaran pokok (gaji, upah), pembayaran prestasi, pembayaran insentif, komisi, bonus, bagian keuntungan, opsi saham, sedangkan pembayaran tertangguh meliputi tabungan hari tua, saham komulatif. Kompensasi finansial tidak langsung. Terdiri atas proteksi yang meliputi asuransi, pesangon, sekolah anak, pensiun. Kompensasi luar jam kerja meliputi lembur, hari besar, cuti sakit, cuti hamil, sedangkan berdasarkan fasilitas meliputi rumah, biaya pindah, dan kendaraan.

2. Kompensasi Non Finansial, Kompensasi non finansial terdiri atas karir yang meliputi aman pada jabatan, peluang promosi, pengakuan karya, temuan baru, prestasi istimewa, sedangkan lingkungan kerja meliputi dapat pujian, bersahabat, nyaman bertugas, menyenangkan dan kondusif.

\section{Indikator Kompensasi}

Indikator dalam pemberian kompensasi untuk karyawan tentu berbeda- beda. Hasibuan (2017:86) mengemukakan secara umum indikator kompensasi, yaitu:

1. Gaji merupakan uang yang diberikan setiap bulan kepada karyawan sebagai balas jasa atas kontribusinya.
2. Upah merupakan imbalan yang diberikan secara langsung kepada karyawan yang didasarkan pada jam kerja

3. Insentif merupakan imbalan finansial yang diberikan secara langsung kepada karyawan yang kinerjanya melebihi standar yang ditentukan

4. Tunjangan merupakan kompensasi yang diberikan kepada karyawan tertentu sebagai imbalan atas pengorbanannya.

PT. Baruna Mitra Segara Lines Panjang merupakan perusahaan pelayaran nasional yang bergerak di bidang jasa pengiriman, melayani Ship Charter, Ship Agency Services, Bunker services dan lain sebagainya, dengan misi memberikan layanan terbaik demi kepuasan dan keberhasilan mitra bisnis pengguna jasa pengiriman. Berdasarkan misi tersebut maka PT. Baruna Mitra Segara Lines Panjang selalu menekankan pada seluruh karyawan untuk mencapai kinerja yang tinggi dan mencapai tujuan organisasi. Untuk mencapai kinerja yang tinggi, senantiasa diperlukan pegawai yang mempunyai kemampuan, keterampilan serta dilakukan pengawasan secara intensif guna terwujudnya tenaga kerja yang produktif, 
sejahtera, berdaya saing serta memiliki kedisiplinan yang tinggi.

Berdasarkan hal tersebut maka PT. Baruna Mitra Segara Lines Panjang memberikan kompensasi berupa kompensasi finansia, kompensasi finansial yang terdiri dari: gaji pokok, insentif yang diberikan setiap satu bulan sekali, bonus tahunan yang diberikan sebesar 2 kali gaji pokok dan Tunjangan Hari Raya (THR) yang diberikan sebesar 1 kali gaji pokok, uang makan dan uang transportasi. Kompensasi berupa gaji dan insentif diberikan satu bulan sekali dan bonus diberikan setiap satu tahun sekali, insenstif dan bonus diberikan kepada seluruh karyawan yang ada di PT. Baruna Mitra Segara Lines Panjang. Berikut ini adalah besaran gaji pokok dan insentif karyawan PT. Baruna Mitra Segara Lines Panjang berdasarkan masa kerja.

Berdasarkan penelitian sebelumnya tentang pengaruh kompensasi perusahaan terhadap kinerja karyawan PT Baruna Mitra Segara Lines Panjang di Bandar Lampung.

\section{METODE PENELITIAN}

Dalam penelitian pengaruh kompensasi perusahaan terhadap kinerja karyawan PT. Baruna Mitra Segara Lines Panjang di Bandar Lampung peneliti menggunakan metode analisis deskriptif dengan pendekatan kuantitatif, yaitu hasil penelitian yang kemudian diolah dan dianalisis untuk diambil kesimpulannya, artinya penelitian yang dilakukan adalah penelitian yang menekankan analisisnya pada data-data numeric (angka), dengan menggunakan metode penelitian ini akan diketahui hubungan yang signifikan antara variabel yang diteliti, sehingga menghasilkan kesimpulan yang akan memperjelas gambaran mengenai objek yang diteliti.

Metode analisis deskriptif adalah statistik yang digunakan untuk menganalisis data dengan cara mendeskripsikan atau menggambarkan data yang telah terkumpul sebagaimana adanya tanpa bermaksud membuat kesimpulan yang berlaku untuk umum atau generalisasi (Sugiono, 2014). Sedangkan dalam Nazir (2003) metode desktiptif yaitu suatu metode dalam meneliti status kelompok manusia, suatu objek, suatu kondisi, suatu pemikiran, ataupun suatu kelas peristiwa pada masa sekarang.

Metode analisis deskriptif adalah statistik yang digunakan untuk menganalisis data dengan cara mendeskripsikan atau menggambarkan data yang telah terkumpul sebagaimana adanya tanpa bermaksud membuat kesimpulan yang berlaku untuk umum atau generalisasi 
(Sugiono, 2014). Sedangkan dalam Nazir (2003) metode desktiptif yaitu suatu metode dalam meneliti status kelompok manusia, suatu objek, suatu kondisi, suatu pemikiran, ataupun suatu kelas peristiwa pada masa sekarang.

\section{Lokasi dan Waktu Penelitian}

Penelitian dilakukan di PT. Baruna Mitra Segara Lines Panjang yang beralamat di Jalan Bahari No.41 Kelurahan Panjang Selatan Kecamatan Panjang Kota Bandar Lampung Provinsi Lampung dengan waktu penelitian selama 1 bulan yaitu sejak 30 Mei 2021 sampai dengan 30 Juni 2021. yang terdiri dari beberapa tahapan dimulai tahap persiapan penelitian berupa penyusunan proposal penelitian, observasi lapangan, pengumpulan data primer dan data sekunder sampai pada tahap pengolahan data dan penarikan kesimpulan.

\section{Jenis dan Sumber Data}

Jenis dan sumber data yang digunakan dalam peneltian ini adalah data primer dan data sekunder. Data primer diperoleh dari hasil penyebaran kuesioner pada sampel yang telah dilakukan, data responden sangat diperlukan untuk mengetahui langsung tanggapan responden mengenai pengaruh kompensasi perusahaan terhadap kinerja karyawan PT. Baruna Mitra Segara Lines Panjang di Bandar Lampung. Untuk data sekunder pengumpulan data dilakukan dari karyawan PT. Baruna Mitra Segara Lines Panjang terkait dengan profil perusahaan, jumlah karyawan, jumlah pendapatan dan pencapaian kerja.

Populasi dalam penelitian ini adalah seluruh karyawan PT. Baruna Mitra Segara Lines Panjang yang berjumlah 150 orang karyawan dengan jumlah sampel dalam penelitian ini adalah 60 orang karyawan PT. Baruna Mitra Segara Lines Panjang.

Rumus yang digunakan untuk mengukur sejauh mana pengaruh kompensasi perusahaan terhadap kinerja karyawan PT. Baruna Mitra Segara Lines Panjang di Bandar Lampung dengan persamaan regresi linear sederhana dengan rumus adalah sebagai berikut :

Menentukan persamaan regresi linear sederhana untuk $\mathrm{X}_{2}$ :

$$
Y=a+b X+e
$$

Keterangan:

$\mathrm{Y} \quad=$ Kinerja karyawan

$\mathrm{X}=$ Kompensasi perusahaan

a $\quad=$ Konstanta

b = Koefisien regresi

$\mathrm{E} \quad=$ Episilon atau variabel yang tidak diteliti

Untuk menguji secara hipotesis secara parsial digunakan Uji t dengan rumus : 


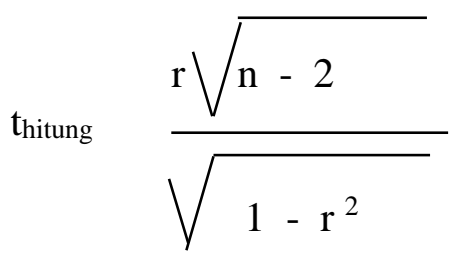

Keterangan:

$\mathrm{t}_{\text {hitung }}=$ Nilai $\mathrm{t}$

$\mathrm{r} \quad=$ Koefisien Korelasi hasil $\mathrm{r}$ hitung

$\mathrm{n} \quad=$ Jumlah responden

Dengan ketentuan :

a) Jika $t_{\text {hitung }}>t_{\text {tabel }}$ maka Ha diterima dan Ho ditolak.

b) Jika $t_{\text {hitung }} \leq t_{\text {tabel }}$ maka Ha ditolak dan Ho diterima.

Untuk mengetahui besarnya pengaruh, penghitungan koefisien korelasi tersebut kemudian dilanjutkan dengan Rumus Koefisien Determinasi $\left(\mathrm{R}^{2}\right)$ :

Adjusted $R^{2}=1-1\left(1-R^{2}\right) \frac{n-1}{n-k}$

Dimana:

$\mathrm{n}$ : Jumlah observasi atau sampel data

$\mathrm{k}$ : Jumlah para meter atau koefisien yang diestimasi,

(Gozhali, 2016:124).

\section{HASIL DAN PEMBAHASAN}

Faktor penyebab pada umumnya dilambangkan dengan $\mathrm{X}$ atau disebut juga dengan predictor sedangkan variabel akibat dilambangkan dengan $\mathrm{Y}$ atau disebut juga dengan response. Berdasarkan hal tersebut maka analisis regresi sederhana yang digunakan dalam penelitian ini adalah untuk mengetahui pengaruh kompensasi perusahaan terhadap kinerja karyawan PT.
Baruna Mitra Segara Lines Panjang di Bandar Lampung. Berdasarkan analisis berikut tabel koefisien regresi :

Tabel 1. Koefisien Regresi.

\begin{tabular}{|l|l|r|r|}
\hline \multirow{2}{*}{\multicolumn{2}{|c|}{ Model }} & \multicolumn{2}{c|}{$\begin{array}{c}\text { Unstandardized } \\
\text { Coefficients }\end{array}$} \\
\cline { 3 - 4 } \multicolumn{2}{|c|}{} & \multicolumn{1}{|c|}{ B } & \multicolumn{1}{c|}{$\begin{array}{l}\text { Std. } \\
\text { Error }\end{array}$} \\
\hline \multirow{2}{*}{1} & (Constant) & 21,151 & 2,813 \\
\cline { 2 - 4 } & $\begin{array}{l}\text { Kompensasi } \\
\text { Perusahaan }\end{array}$ &, 530 &, 069 \\
\hline
\end{tabular}

a. Dependent Variable: Kinerja Pegawai

Berdasarkan tabel di atas maka diperoleh hasil persamaan regresi sebagai berikut:

$$
Y=21.151+0.530 X
$$

Artinya jika kompensasi perusahaan diasumsikan meningkat sebesar 1 poin maka kinerja kayawan akan meningkat sebesar 0.530 poin pada konstanta 21.151 Sehingga dengan demikian dapat diketahui bahwa semakin tinggi kompensasi yang diberikan perusahaan kepada karyawan maka kinerja karyawan PT. Baruna Mitra Segara Lines Panjang di Bandar Lampung akan semakin meningkat sehingga semua program atau beban kerja yang diberikan kepada karyawan PT. Baruna Mitra Segara Lines Panjang di Bandar Lampung mampu dijalankan dengan maksimal serta targettarget akan tercapai sesuai dengan perencanaan yang sudah di susun sehingga juga akan berdampak pada semakin 
meningkatnya pendapatan atau laba Tabel 3. Koefisien Detererminasi.

perusahaan.

Berdasarkan uji hipotesis dapat dilihat dalam tabel Uji t-Statistik dibawah ini:

Tabel 2. Uji t Statistik

\begin{tabular}{|c|c|c|c|c|c|c|}
\hline \multirow{2}{*}{\multicolumn{2}{|c|}{ Model }} & \multicolumn{2}{|c|}{$\begin{array}{c}\text { Unstandardi } \\
\text { zed } \\
\text { Coefficients }\end{array}$} & \multirow{2}{*}{$\begin{array}{l}\text { Standardize } \\
\mathrm{d} \\
\text { Coefficients } \\
\text { Beta }\end{array}$} & \multirow[t]{2}{*}{$\mathrm{t}$} & \multirow{2}{*}{$\begin{array}{l}\text { Sig } \\
\text {. }\end{array}$} \\
\hline & & B & $\begin{array}{l}\text { Std. } \\
\text { Error }\end{array}$ & & & \\
\hline \multirow[t]{2}{*}{1} & $\begin{array}{l}\text { (Con } \\
\text { stant } \\
)^{2} \\
\end{array}$ & $\begin{array}{r}21,1 \\
51\end{array}$ & 2,813 & & 7,520 &, 000 \\
\hline & $\begin{array}{l}\text { Kom } \\
\text { pens } \\
\text { asi } \\
\text { Peru } \\
\text { saha } \\
\text { an }\end{array}$ &, 530 & ,069 & ,711 & 7,696 & ,000 \\
\hline
\end{tabular}

a. Dependent Variable: Kinerja Pegawai

Berdasarkan tabel di atas maka nilai thitung variabel kompensasi perusahaan sebesar 7.696 sedangkan $t_{\text {tabel }}$ sebesar 1.671 , jadi $t_{\text {hitung }} 7.696>t_{\text {tabel }} 1.671$, serta nilai signifikasi (sig t) sebesar $0.000<0.05$ dengan demikian Ho ditolak Ha diterima. Sehingga dapat disimpulkan bahwa kompensasi perusahaan berpengaruh dengan positif dan signifikan terhadap kinerja karyawan PT. Baruna Mitra Segara Lines Panjang di Bandar Lampung dengan demiksian hipotesis dalam penelitian ini terdukung.

Hasil perhitungan Koefisien Determinasi $\left(\mathrm{R}^{2}\right)$ dapat dilihat pada tabel di bawah ini:

\begin{tabular}{|l|r|l|r|r|}
\hline Model & $\mathrm{R}$ & $\begin{array}{l}\mathrm{R} \\
\text { Square }\end{array}$ & $\begin{array}{r}\text { Adjusted } \\
\text { R Square }\end{array}$ & $\begin{array}{r}\text { Std. Error } \\
\text { of the } \\
\text { Estimate }\end{array}$ \\
\hline 1 &, $711^{\mathrm{a}}$ &, 505 &, 497 & 2,93297 \\
\hline
\end{tabular}

a. Predictors: (Constant), Kompensasi Perusahaan

Berdasarkan tabel di atas menjelaskan besarnya kinerja karyawan yang dipengaruhi oleh variabel bebasnya. Pada hasil di atas Koefesien Determinasi ( $R$ Square) sebesar 0.505 artinya kompensasi perusahaan memiliki pengaruh sebesar $50.5 \%$ terhadap kinerja karyawan PT. Baruna Mitra Segara Lines Panjang di Bandar Lampung. Sedangkan sisanya 49.5\% kinerja karyawan PT. Baruna Mitra Segara Lines Panjang di Bandar Lampung.

Hasil penelitian tersebut sesuai dengan hasil penelitian yang dilakukan oleh Agung Surya Dwianto, Pupung Purnamasari dan Tukini (2019) yang menjelaskan bahwa hasil uji t-test yang telah dilakukan maka dapat dilihat bahwa terdapat pengaruh positif yang signifikan antara kompensasi terhadap kinerja karyawan bagian produksi PT. Jaeil Indonesia dengan menunjukkan nilai $\rho$ lebih kecil dari nilai $\alpha(0,000<0,05)$ dan nilai $\mathrm{t}$ hitung $>\mathrm{t}$ tabel $(5,146>2,04841)$. Artinya kompensasi dapat meningkatkan 
kinerja karyawan (semakin tinggi Lines Panjang di Bandar Lampung yang kompensasi maka semakin tinggi pula dilihat dari nilai thitung sebesar 7.696 kinerjanya). Jika pemberian kompensasi sedangkan $t_{\text {tabel }}$ sebesar 1.671, jadi tinggi maka diharapkan tanggung jawab $t_{\text {hitung }} 7.696>t_{\text {tabel }} 1.671$, serta nilai kinerja yang harus diberikan oleh karyawan signifikasi (sig t) sebesar $0.000<0.05$. juga tinggi. Maka akan menguntungkan kedua belah pihak.

Besarnya tingkat kompensasi yang diberikan kepada karyawan maka karyawan akan merasa puas dan kebutuhan sehari-hari dapat terpenuhi, karyawan PT. Baruna Mitra Segara Lines Panjang di Bandar Lampung merasa puas dengan apa yang mereka terima sepadan dengan hasil kerja mereka, mereka termotivasi dalam mengerjakan pekerjaan yang telah menjadi bagian mereka dan bersungguh- sungguh dalam bekerja, karyawan yang bersungguhsungguh dalam mengerjakan sesuatu dipastikan kecil kemungkinan melakukan kesalahan, disini kinerja karyawan akan terukur bahwa karyawan yang merasa puas dipastikan kinerjanya akan menigkat.

\section{KESIMPULAN}

Berdasarkan analisis data dan pembahasan pada bab sebelumnya, diperoleh simpulan sebagai berikut kompensasi perusahaan berpengaruh dengan positif dan signifikan terhadap kinerja karyawan PT. Baruna Mitra Segara Selain itu dilihat dari hasil perhitungan Koefisien Determinasi $\left(\mathrm{R}^{2}\right)$ atau sumbangan efektif yang dapat diberikan variabel kompensasi perusahaan terhadap kinerja karyawan dari analisis diperoleh nilai atas Koefesien Determinasi ( $R$ Square) sebesar 0.505 artinya kompensasi perusahaan memiliki pengaruh sebesar $50.5 \%$ terhadap kinerja karyawan PT. Baruna Mitra Segara Lines Panjang di Bandar Lampung.

\section{SARAN}

Berdasarkan kesimpulan di atas maka dapat diberikan saran sebagai berikut:

1. PT. Baruna Mitra Segara Lines Panjang di Bandar Lampung dalam memberikan kompensasi hendaknya lebih mempertimbangkan pengalaman kerja, pendidikan karyawan, beban kerja yang diberikan kepada karyawan serta bagi karyawan baru hendaknya perusahaan menginformasikan kompensasi yang akan diterima ketika bekerja di perusahaan sehingga tidak terjadi 
kesalahan pahaman dan merasa ada yang di rugikan.

2. Hendaknya karyawan mampu untuk meningkatkan kinerja dengan selalu: (a) mengembangkan potensi yang dimiliki dan didorong dengan motivasi kerja yang tinggi untuk dapat mencapai tujuan organisasi yang diharapkan, (b) meningkatkan disiplin kerja dengan kesadaran dan tanggung jawab yang tinggi untuk menuntaskan semua pekerjaan yang sudah ditargetkan oleh organisasi

\section{UCAPAN TERIMAKASIH}

Terimakasih kepada Universitas Sang Bumi Ruwa Jurai yang telah berkontribusi dalam penelitian ini

\section{DAFTAR PUSTAKA}

Agung Surya Dwianto, Pupung Purnamasari dan Tukini. 2019. Pengaruh Kompensasi Terhadap Kinerja Karyawan Pada PT. JAEIL Indonesia, Jurnal Ekonomi \& Ekonomi Syariah Vol 2 No 2, Juni 2019.

Dessler, Gary. 2019. Manajemen SDM. Jakarta : Indeks.

Dharma, Surya. 2015. Manajemen Kinerja; Falsafah Teori dan Penerapannya. Yogyakarta : Pustaka Pelajar.

Hasibuan, Malayu. 2017. Manajemen Prestasi Kerja. Jakarta : CV Rajawali.
Mangkunegara, A.A. Anwar Prabu. 2015. Evaluasi Kinerja SDM. Bandung : Refika Aditama.

Murphy, Kevin R. Jeanette N. Cleaveland. 2018. Understanding Performance Appraisal : Social, Organization and Goal-Based Perspectives. California :Sage Publications.

Prawirosentono, Suyadi. 2017. Manajemen Sumber Daya Manusia: Kebijakan Kinerja Karyawan. Edisi 1. Cetakan Kedelapan. Yogyakarta : BPFE.

Rivai dan Basri. 2015. Manajemen Sumber Daya Manusia Untuk Perusahaan. Jakarta : Rajagrafindo Persada.

Rivai, Veithzal dan Ella, Jauvani, Sagala. 2017. Manajemen Sumber Daya Manusia untuk Perusahaan dari Teori ke Praktik. Jakarta : PT Raja Grafindo.

Suparyadi. 2015. Manajemen Sumber Daya Manusia. Yogyakarta : Andi.

Timpe, A. Dale. 2018. Seri Manajemen Sumber Daya Manusia (Kinerjal Performace). Jakarta : PT. Elek Media Kaputindo.

Widodo, Suparno, Eko. 2015. Manajemen Pengembangan Sumber Daya Manusia. Yogyakarta : Pustaka Pelajar. 